\title{
FASILITAS BELAJAR BISNIS DAN DESAIN TATA BUSANA DI TANAH ABANG
}

\author{
Georgia Christin ${ }^{1)}$, Nina Carina²) \\ 1) Program Studi S1 Arsitektur, Fakultas Teknik, Universitas Tarumanagara, giachristin@gmail.com \\ 2)Program Studi S1 Arsitektur, Fakultas Teknik, Universitas Tarumanagara, nincarin@gmail.com
}

\begin{abstract}
Abstrak
Belakangan ini bisnis e-commerce di Indonesia sedang menggalami kenaikan pengguna yang signifikan. Menurut data statistik salah satu kategori produk yang paling diminati dalam $e$ commerce adalah di bidang fashion. Dimasa ini Generasi Milenial menginjak usia produktif, tetapi yang sangat amat disayangkan bahwa, hanya 1 dari 4 milenial yang ingin terlibat dalam perusahaan. Hal ini dikarenakan sistem kerja yang terbentuk tidak cocok dengan karakteristik milenial yang bebas dan lebih suka berbisnis. Proyek ini membahas bagaimana meningkatkan peran Generasi Milenial untuk dapat terjun ke dunia bisnis fashion yang mempunyai peluang pasar yang besar. Tujuannya agar milenial dapat belajar membuka bisnis sendiri di bidang fashion serta mempersiapkan kebutuhan berbisnis di dunia fashion melalui Fasilitas Belajar Bisnis \& Desain Tata Busana. Dengan demikian di masa depan generasi milenial dapat langsung terjun di dunia fashion. Perancangan ini berlokasi di Tanah Abang dan memakai metode Pedagogy Linking Space oleh Dr. Kenn Fisher. Fasilitas belajar ini di desain sesuai dengan karakteristik milenial yang suka berkolaborasi dan berdiskusi.
\end{abstract}

Kata kunci: fashion; kolaborasi; milenial

\begin{abstract}
Recently e-commerce businesses in Indonesia are experiencing a significant increase in users. According to statistical data, one of the most popular product categories in e-commerce is the fashion sector. This dimension of the Millennial Generation was stepped into productive age, but it is very unfortunate, only 1 in 4 millennia wants to be involved in the company. This is related to the work system that is formed not in accordance with millennial characteristics that are free and prefer to do business. This project discusses how to enhance the role of the Millennial Generation to be able to enter the business world that has a large market opportunity. The goal is that millennials can be studied opened in the field of fashion and also prepared to do business in the fashion world through Business Learning Facilities \& Fashion Design. Thus in the future the millennial generation can immediately jump in the fashion world. This design was placed in Tanah Abang and used the Pedagogy of Connecting Space method by Dr. Kenn Fisher. Learning facilities are designed according to the characteristics of the military who like to collaborate and discuss.
\end{abstract}

Keywords: collaborative; fashion; millennials

\section{PENDAhuluan}

Menurut data Badan Pusat Statistik (BPS) yang dirilis tahun 2016, menemukan fakta bahwa kelompok usia produktif mendominasi angkatan kerja adalah usia 15-39 tahun dengan 84,75 juta dari total penduduk Indonesia yang sejumlah 258 juta. Artinya sekitar 32\% penduduk Indonesia adalah usia produktif yang sekarang ini merupakan generasi $Y$, atau disebut dengan generasi millennials. Selain itu, riset yang dilakukan oleh Price Waterhouse Cooper pada tahun 2017, persentase pekerja secara global akan didominasi oleh generasi millennial sebanyak 50\% di tahun 2020 mendatang. Hal ini memberikan pernyataan bahwa generasi milenial akan berangsur-angsur menjadi generasi dengan usia produktif terbesar dan menggantikan generasi $X$. Sehingga, dalam waktu yang amat singkat generasi milenial akan menggantikan generasi $X$ sebagai angkatan kerja di usia produktif (Smith and Nicholas, 2015). 
Pada nyatanya yang amat disayangkan adalah, bahwa milenial enggan untuk bekerja terlibat pada perusahaan seperti yang dilakukan oleh Generasi X. Perbandingannya hanya 1 dari 4 tenaga kerja milenial, yang terlibat sepenuhnya dalam perusahaan. Tak hanya itu, survei juga menunjukkan, $64 \%$ di antara terlibat sepenuhnya pasti akan bertahan setidaknya setahun ke depan. Sebaliknya, 60\% milenial berencana mengundurkan diri apabila merasa disengaged. (rappler.com)

Diperkuat oleh riset yang dilakukan oleh Forbes bahwa sebanyak $43 \%$ milenial berencana untuk berhenti dalam pekerjaan mereka dalam kurun waktu dua tahun. Salah satu alasan utamanya adalah, kebebeasan atau fleksibel dalam pembagian waktu. Generasi ini lebih suka bekerja bebas untuk mengemukakan ide daripada menjadi karyawan di kantor biasa. (Whiteboard Journal, 2018). Karena hal ini dianggap membosankan dan mengharuskan milenial bekerja dalam sistem yang telah diatur, sehingga membuat generasi ini menjadi susah mengekspresikan ide dan gagasannya sendiri.

Selain itu tercantum di riset Millenial Behaviour yang dilakukan oleh Richard T. Sweeney dalam pembahasan cara bekerja. Mereka ingin mempunyai waktu yang fleksibel dan tidak ingin menghabiskan kehidupannya dengan cara-cara lama bekerja dan waktu kerja yang ketat. Oleh karena itu dapat kita jumpai di banyak perusahaan yang bahwa pemiliknya yang merupakan bagian dari generasi milenial dikarenakan hal di atas. Hal itu juga di dorong karena sifat milenial yang selalu ingin menciptakan hal baru dengan cara membuka bisnis sendiri sebagai freelancer atau sociopreneur.

Menurut sekolah bisnis Universitas Prasetya Mulya, dalam berbisnis pilihan generasi milenial dalam bisnis kreatif salah satu diantaranya adalah bisnis online (e-commerce). Bisnis yang pemasarannya berbasis dengan penggunaan teknologi. Alasan generasi milenial memilih bisnis kreatif online ini dikarenakan hal ini lebih menguntungkan baik untuk jangka panjang ataupun jangka pendek. Kemampuan generasi milenial dalam mengamati kebutuhan pasar dan ditambah dengan cara memanfaatkan setiap teknologi yang ada, sehingga membuatnya memiliki peluang lebih besar untuk unggul dalam bidang bisnis online. Contoh bisnis online yang banyak digeluti para milenial adalah produk fashion, produk kecantikan, gadget, dll.

Salah satu ekonomi digital yang ditekuni dan banyak digemaari adalah industri fashion. Badan Ekonomi Kreatif (BeKraf) Indonesia mencatat bahwa pada tahun 2015 industri fashion terletak di posisi ke dua terbesar yang telah menyumbang kontribusi terhadap PDB (Pendapatan Domestik Bruto) nasional di Indonesia sebesar 3,76 persen, dengan tingkat nilai ekspor bidang industri kreatif tertinggi pada tahun 2015 mencapai USD 13,29 milyar, serta telah meningkat 8,7 persen dari tahun sebelumnya.

Hal ini merupakan peluang bisnis bagi generasi milenial, dengan data statistik yang menunjukan peningkatan angka PDB menunjukan minat bahwa adanya permintaan yang kuat serta ketertarikan akan produk fashion baik dari generasi milenial maupun generasi sebelumnya atau sesudahnya.

Maka dari itu, program yang diusulkan adalah wadah/fasilitas belajar bagi milenial seputar fashion agar generasi ini dapat menciptakan suatu produk bisnis, yang mana milenial harus terlebih dahulu menguasai dan mempelajari beberapa kategori dan karakterisitik produk fashion yang nantinya akan dijual, untuk itu milenial memerlukan adanya fasilitas belajar yang memadai dalam menciptakan produk fashion yang berkualitas berdasarkan target pasar milenial. Sehingga dengan mempunyai product knowledge di bidang fashion milenial diharapkan dapat mengambil kesempatan peluang yang besar di pasar e-commerce fashion.

\section{KAJIAN LITERATUR}

Generasi millennial (juga dikenal sebagai Generasi Y) adalah kelompok demografi setelah Generasi X (Gen-X). Tidak ada batas waktu yang pasti untuk awal dan akhir dari kelompok ini. Para ahli dan peneliti biasanya menggunakan awal 1980-an sebagai awal kelahiran dari kelompok ini dan pertengahan tahun 1990-an hingga awal 2000-an sebagai batas akhir kelahiran generasi ini. (Fourhooks, 2015). 
Setiap generasi pada zamannya mempunyai karakteristik yang masing-masing memiliki perbedaan. Sebagai contoh, generasi milenial adalah generasi pertama yang menghabiskan waktu di lingkungan digital; informasi teknologi sangat memengaruhi bagaimana cara generasi milenial hidup dan bekerja (Bennett, Maton, \& Kervin, 2008; Wesner \& Miller, 2008).

Menurut Whiteboard Journal, Generasi Millennial tidak suka di atur dan ingin memiliki kebebasan terhadap kehidupannya. Selain itu, flesksibilitas menjadi hal yang utama dikarenakan kebiasaan generasi ini dengan pola kerja yang dinamis, sehingga mereka membutuhkan lingkungan kerja yang mendukung habit tersebut. Tidak hanya itu, generasi ini mempunyai kemampuan untuk bisa menyelesaikan pekerjaan di satu tempat yang dapat lebih meningkatkan produktivitas dan mempengaruhi semangat mereka dalam kualitas pekerjaannya.

Hasil studi riset yang dilakukan oleh Dale Carnegie Indonesia yang berjudul 'Employee Engagement Among Millennials' di tahun 2016 menjelaskan bawah hanya 25\% tenaga kerja millenial (kelahiran 1986-2000) yang terlibat sepenuhnya (fully engaged) dengan perusahaan tempat mereka bekerja. Selebihnya, terdapat $65 \%$ (partially engaged) yang setengah terlibat dan $9 \%$ (disengaged) yang tidak ingin sama sekali terlibat dengan perusahaan. Minat generasi terhadap kerja yang padat sangat sedikit, Maka dari itu, Generasi Millennials lebih menyukai waktu kerja yang fleksibel, biasanya lebih dikenal dengan profesi freelancer dan entrepreneurship.

Di Indonesia, sektor industri merupakan komponen utama dalam pembangunan ekonomi nasional. Saat ini, persaingan antar perusahaan dari berbagai sektor industri semakin ketat. Salah satu sektor industri bisnis yang sedang banyak digeluti yaitu pada industri fashion. Di Indonesia saat ini berkembang dengan sangat pesat. Kondisi tersebut sejalan dengan semakin berkembangnya kesadaran masyarakat akan fashion yang sudah mengarah pada pemenuhan gaya hidup dalam berbusana, sehingga dapat dikatakan bahwa kebutuhan berbusana pada zaman sekarang tidak hanya untuk menutupi tubuh, tetapi juga sebagai sarana berkomunikasi dan menunjukkan gaya hidup dan identitas pemakaianya.

Pada realitanya model fashion selalu cepat berubah, berkembang, dan bergulir dari tahun ke tahun, sesuai dengan ide pemikiran manusia, dan perkembangan teknologi, disertai kondisi zaman sekarang ini. Perkembangan fashion, model busana, dan lain-lain di Indonesia sudah sangat tinggi peminatnya, karena seperti yang kita ketahui pakaian merupakan salah satu kebutuhan primer yang dibutuhkan oleh manusia.

Menurut Menteri Perindustrian Saleh Husin, industri fashion di Indonesia pada tahun 2015 telah melesat menjadi salah satu primadona subsektor industri kreatif bahkan sektor ekonomi kreatif memberikan kontribusi sebesar 641,8 trilyun Rupiah terhadap PDB Indonesia, sedikit di atas sektor pengangkutan dan komunikasi, serta sektor keuangan, real estate, dan jasa perusahaan. Dari jumlah tersebut, subsektor fashion menyumbang sebesar $28,29 \%$ atau setara dengan 181,5 trilyun Rupiah, kedua terbesar setelah subsektor kuliner (208,6 trilyun Rupiah). Subsektor fashion juga menyerap tenaga kerja paling banyak di antara subsektor industri kreatif lain, yaitu 3.838.756 orang dari 1.107.956 unit usaha dan laju pertumbuhan ekspor tertinggi di antara subsektor industri kreatif (9,51\%), fashion berkontribusi sebesar 76,78 trilyun Rupiah terhadap ekspor Indonesia (Kemenperin, 2015). Hal ini dapat memberikan dampak positif bagi para pelaku bisnis di Indonesia yang bergerak di bidang Industri fashion untuk lebih mengembangkan usahanya.

Menurut teori Dr. Kenn Fisher di artikel linking pedagogy and space terdapat beberapa panduan tahapan sebelum mendesain sebuah bangunan edukasi. Tahapan tersebut terbagi kedalam empat fase tema yaitu curriculum context, pedagogy + space, planning principle, dan studi kasus. Berikut akan dibahas per tema sesuai dengan tahapannya.

Langkah awal pada bangunan ini, yaitu curriculum context yang artinya untuk menentukan cakupan subjek bidang yang akan dibangun di fungsi ini. Terdapat beberapa pilihan dan tujuan untuk sebuah bangunan. Misalnya bangunan learning center dengan sasaran orang yang sudah lulus sekolah dan ingin mengembangkan kemampuan fashionnya. Subjek bidang ini akan 
memberikan pengajaran yang mengarah pada pertumbuhan ide kreatif desain dan penggabungan bentuk fashion yang estetik. Serta pada penentuan tahapan akhir program ini akan menggunakan metode penyampaian dengan menyampaikan materi (delivering), pengaplikasian (applying), menghasilkan suatu output (creating) dan komunikasi yang terarah (communicating) dan decision making.

Langkah ke dua yaitu, pedagogy and space setelah menentukan cakupan subjek bidang dan cara pengaplikasian subjek tersebut ke pihak lain, terdapat beberapa detail suatu ruangan yang perlu diperhatikan agar tercapai tujuan bersama. Dengan teknik penyampaian yang telah ditentukan terdapat beberapa aturan dan tujuan untuk menentukan detail dan tujuan setiap ruangan memberikan efektivitas dan menunjang keberhasilan suatu materi.

Dari gambar di atas, dapat diketahui dengan detail ruang apa saja yang akan terbentuk sesuai dengan kebutuhan bangunan Fashion Business Learning Space. Pada proses delivering membutuhkan ruangan yang fokus pada satu titik untuk menyampaikan materi dengan audience yang banyak. Proses applying membutuhan ruang studio untuk mencoba hal yang sudah disampaikan pada proses sebelumnya (menjahit). Proses creating menyediakan ruangan studio yang mendorong kreativtas pada pihak yang bersangkutan untuk menciptakan atau memcahkan permasalahan secara bersamaan (kolaboratif) atau sendiri (individual). Proses communicating dan decision making memberikan ruangan sebagai sarana pihak yang bersangkutan untuk menyampaikan komunikasi dan tempat berpikir untuk menyelesaikan permasalahan soal.

Selain itu terdapat banyak jenis ruangan yang dapat digabungkan teknik satu dengan yang lainnya agar menjadi kualitas ruang yang dapat menunjang berbagai aktivitas. Beragam contoh kualitas ruang juga dapat dilakukan dengan pengalaman ruang outdoor untuk memanfaatkan sumber daya pencahayaan alami. Berikut merupakan beberapa kualitas ruang yang tercipta dari teknik penerapan di atas.

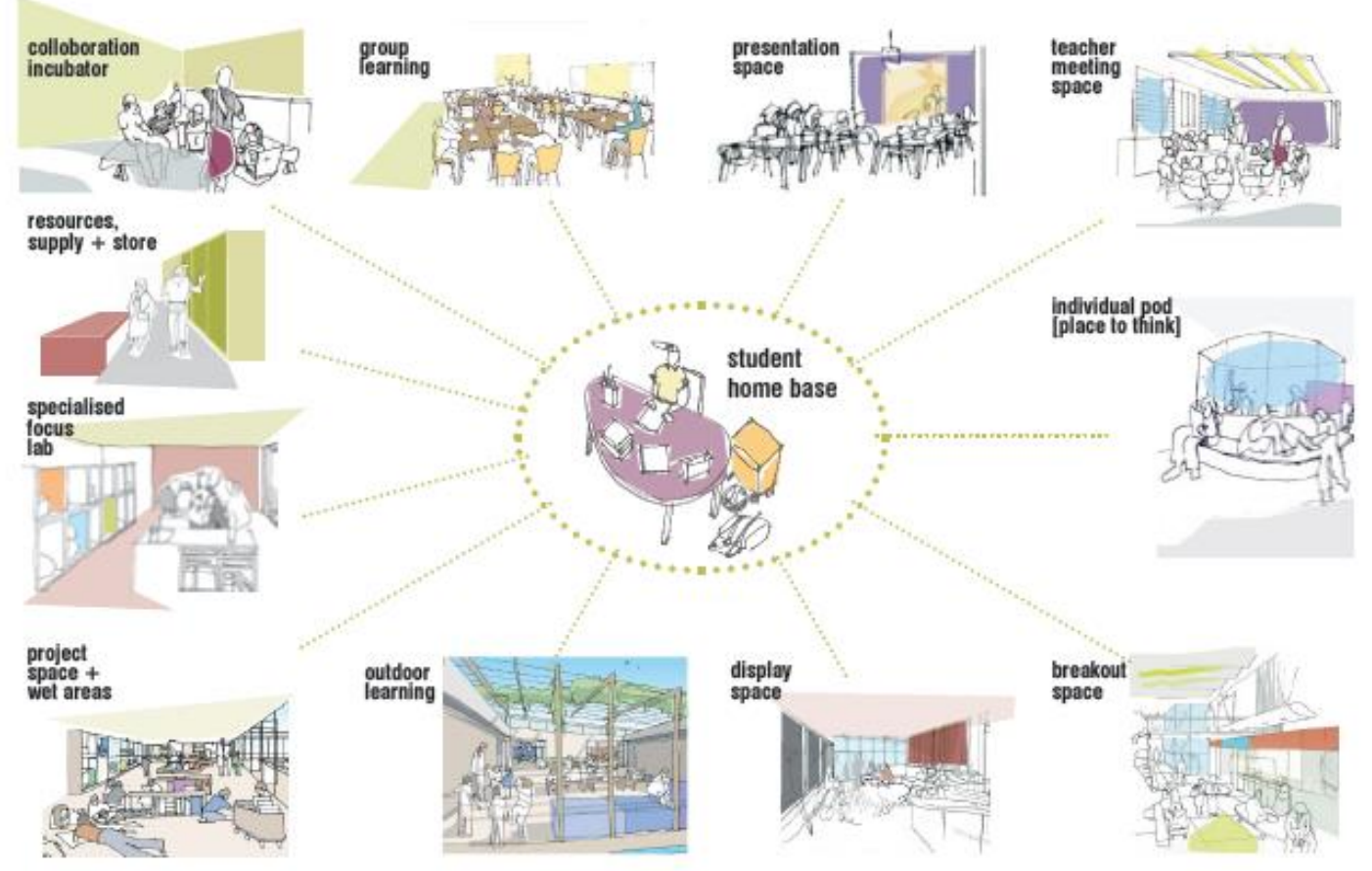

Gambar 1. Pedagogy Method

Sumber: Fisher, 2005

Terbagi kedalam lima bagian ruangan sebagai penunjang untuk fungsi bangunan ini yaitu individual settings, group settings, activity rich settings, informal settings, dan staff settings. Masing-masing ruangan mempunyai sasaran dan tujuan yang berbeda sesuai dengan detail dan kualitas ruangannya. Berikut merupakan penjelasannya: 
a. Kualitas ruang individual (individual settings), ruangan yang cocok untuk individu bekerja dan berpikir (personal space).

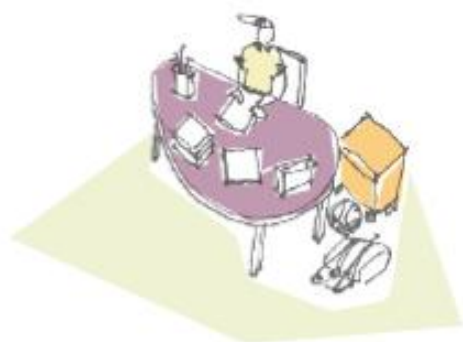

student home base

\section{space}

Space for an individual to peraonalise and in which to work and study.

Gathering place for leamers and teachers.

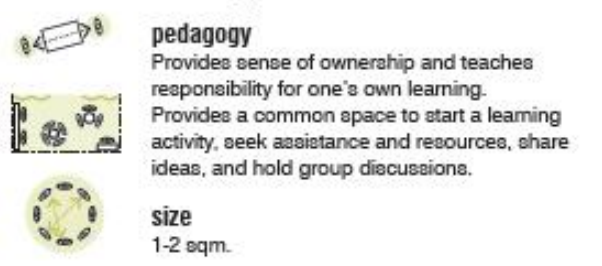

\section{Gambar 2. Individual Settings}

Sumber: Fisher, 2005

b. Kualitas ruang untuk group (group settings), bentukan ruangan yang cocok untuk sebuah grup berdiskusi sehngga dapat tercipta suasana ruang yang kondusif

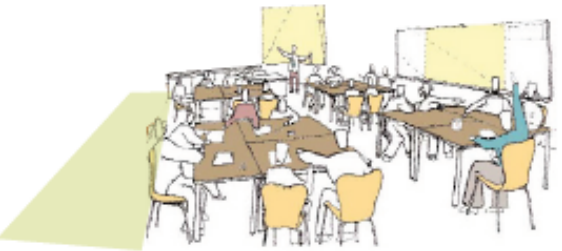

group learning space

space

Individual or team spaces for staff that has adjacent

material preparation area and meeting space.

\section{pedagogy}

Encourages team teaching, mentoring of

other faculty, integrated planning, and informal

粠.

diecuesions.

size

$20-25$ sqm.

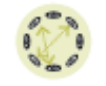

.

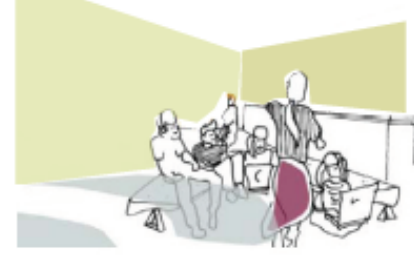

collaboration incubator

space

Idea generation space, team meeting space, accese to technology and other reeources and dieplay apace for models and ideas.

\section{pedagogy}

Support creativity, idea generation, teamwork and prototyping of concepte.

Encourages involvement of local employers in the development of projects.

size

20 sqm.

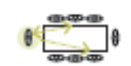

Gambar 3. Group Settings

Sumber: Fisher, 2005 


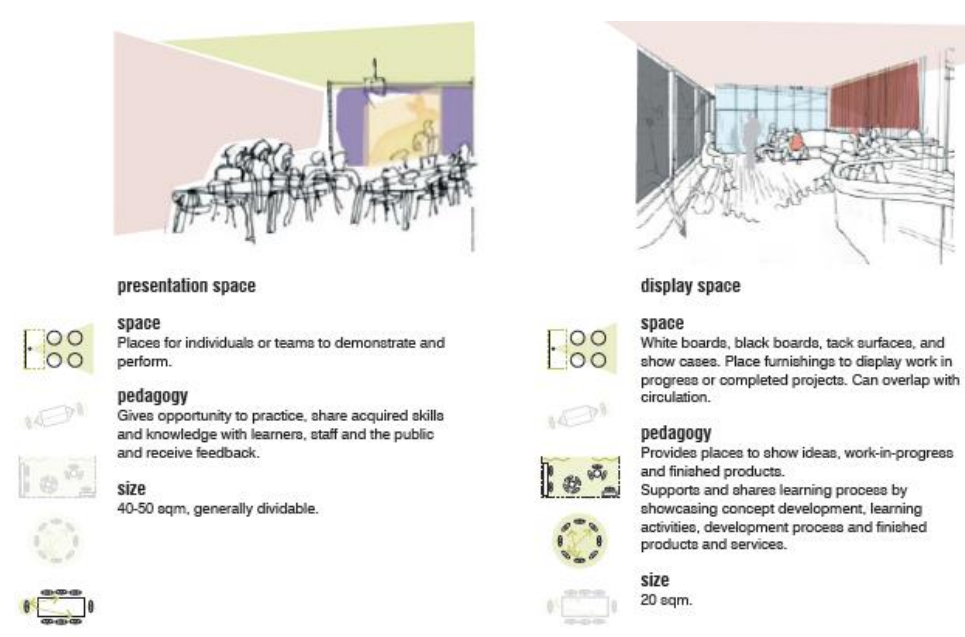

Gambar 4. Group Settings

Sumber: Fisher, 2005

c. Kualitas ruang untuk program utama (activity rich settings), jenis ruangan yang dapat merangsang berbagai kreatifitas student dalam membuat suatu project.

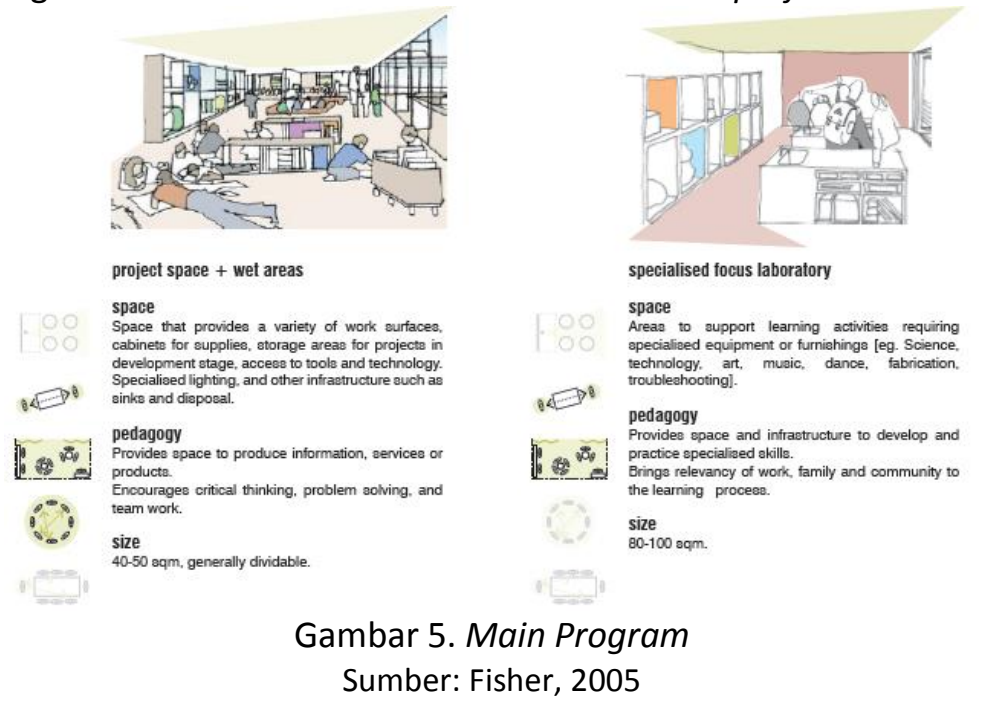

d. Kualitas ruang untuk program penunjang (informal settings), ruangan yang menunjang dari kegiatan aktivitas utama seperti; tempat beristirahat dll

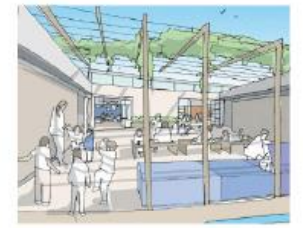

outdoor learning

space

Outdoor areas of any scale that are semi-defined by landscape, building edge or lightweight cover, with

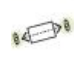

pedagogy

Provides informal outdoor area for socialising

or structured small group act

size

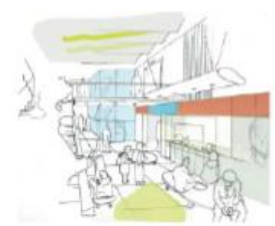

'breakout' spaces

space

Lounge areas, small study roome, widened corridor ppaces that allow gathering away from formal

Q $\leftrightarrow 9$ pedagogy

Provides peychological and phyeiological relief from

formal environmente. Allows for individual reflection.

groupe.

size

Gambar 6. Informal Settings

Sumber: Fisher, 2005 
e. Kualitas ruang untuk para staff (staff settings)

Ruang ini dikhususkan untuk para staff pekerja untuk bertukar ide pikiran dalam memberikan suatu materi dan adanya pusat interaksi antar staff.

Langkah ke tiga adalah planning principle, yaitu memberikan zona-zona hubungan ruang yang berkaitan satu dengan yang lain. Menetapkan fungsi ruang-ruang yang dikaitkan satu dengan yang lainnya. Permisalan dengan ruangan di atas yang terbentuk adalah ruangan workshop (applying\&creating) yang dapat didekatkan ruangan yang dapat menunjang kegiatan tersebut seperti dengan perpustakaan atau display kreatif yang dapat menberikan inspirasi serta harus dekat dengan akses sarana toilet atau pantry untuk jeda singkat. Penghubung antar ruangan ini akan menjadi titik temu semua pihak di training center dan akan menjadi shared place atau ruang publik untuk berbagai aktivitas sharing ilmu dan yang lainnya bagi sesama pengunjung di tempat ini.

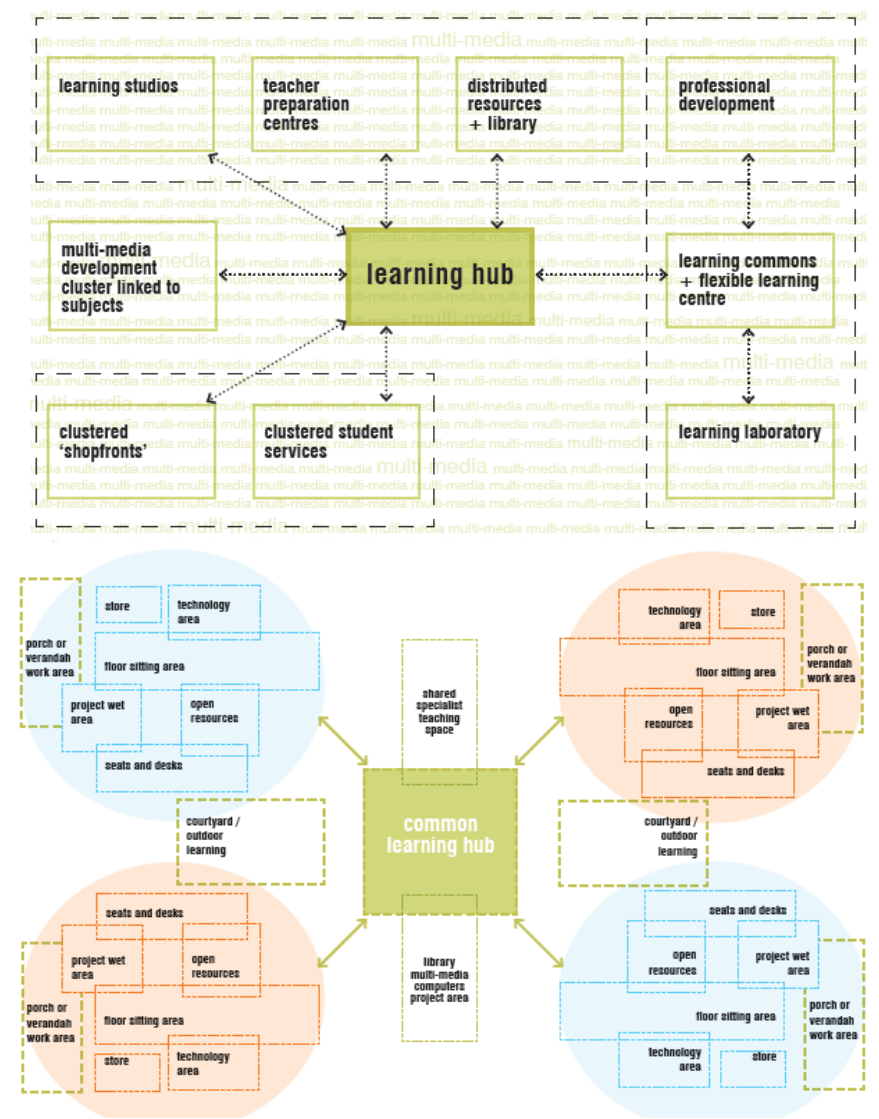

Gambar 7. Planning Principle

Sumber: Fisher, 2005

Langkah ke empat, studi kasus. Sebelum mendesain suatu ruangan ada baiknya jika terdapat referensi dari project lainnya juga.

\section{METODE}

Metode yang digunakan adalah 'The PSD (Pedagogical Space Design) Method' oleh Dimitris Germanos membahas bahwa pentingnya sebuah ruangan di sekolah dapat mendukung pengajaran kurikulum yang sedang berlaku, sehingga ruangan yang tercipta dapat memberikan suasana yang kondusif dan kooperatif . Metode ini dijadikan pedoman untuk mendesain bangunan berfungsi pendidikan agar ruang yang tercipta menjadi bermanfaat dan efisien. Terdapat beberapa rules yang dikeluarkan oleh metode ini yaitu (1) the organization of space in activity area, (2) space flexibility, (3) creating a familiar atmosphere, (4) the creation of micro environments for individual and group. 
Selain itu terdapat empat direction yaitu: (1) the creation of space and stimuli (2) second direction, (3) the creation of educational "places: in the space . Cara menggunakan metode ini adalah rules yang diberikan disandingkan dengan direction sehingga menjadi suatu kesimpulan hasil ruang yang harus diciptakan. Berikut merupakan hasil matrix yang sudah disandingkan serta kesimpulan rungan dengan ilustrasinya.

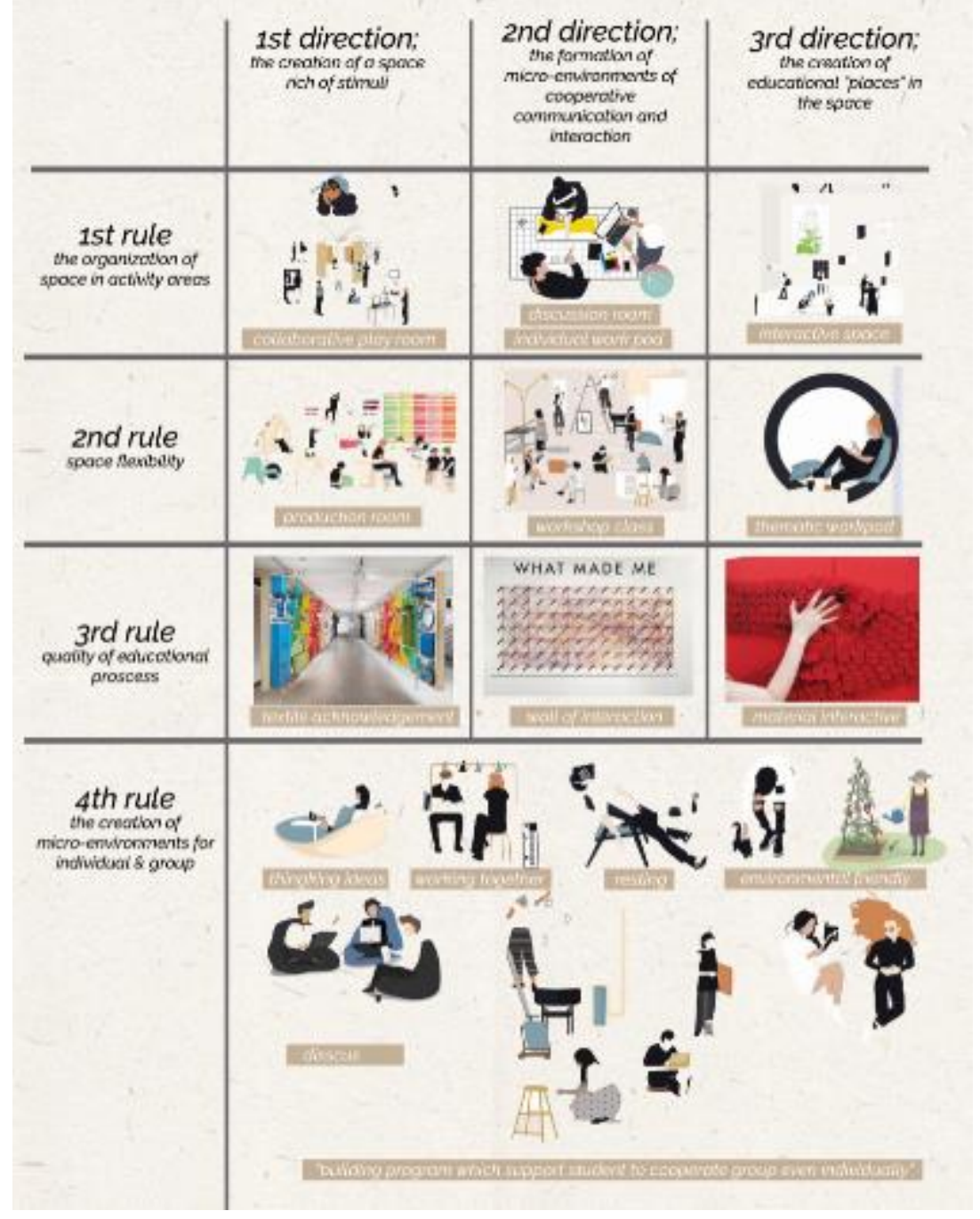

Gambar 8. Matrix Method

Sumber: Penulis, 2019

Selain itu, pemilihan tapak bangunan ini terletak di kecamatan Palmerah dengan luasan tapak $5100 \mathrm{~m} 2$. Tapak yang dipilih sudah sesuai dengan kriteria dan melewati analisa (eliminasi) alternative dari 4 tapak yang berada di Kecamatan Tanah Abang dan Kecamatan Palmerah. Berikut adalah beberapa poin dari kriteria tapak yang dibutuhkan; (1) Berdekatan dengan Pasar Tanah Abang untuk memudahkan proses loading, (2) berdekatan dengan transportasi umum yang mudah dicapai, (3) terintegrasi dengan jalan besar sehingga mudah ditemukan, (4) Berada di lokasi zonasi peruntukan pendidikan (S1) atau di bidang jasa (K2 dan K4), (5) dekat dengan titik pusat perbelanjaan sehingga barang yang dihasilkan dapat langsung dijual atau dapat menjadi tenant di mall, (6) dekat dengan pusat keramaian dll. Berikut merupakan analisa studi tapak terpilih. 


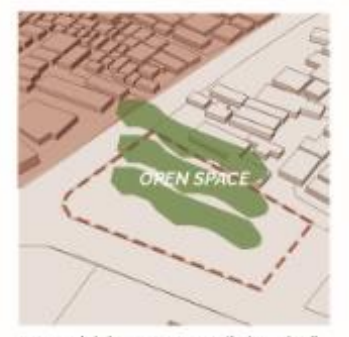

rencerva lefat open spoce yatu beroda di tangan bongunan agar masso bangunon ticiah

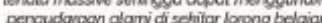

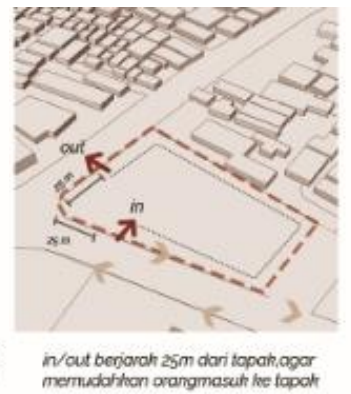

memudathon arangmasuth he fapoh

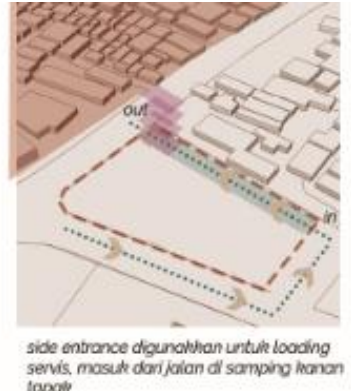

\section{Gambar 9. Analisa Tapak}

Sumber: Penulis, 2019

Setelah analisa tapak langsung lanjut pada proses gubahan massa yang dibuat dengan memerhatikan konteks sekitar dari hasil analisa tapak diatas. Terdapat enam proses pembentukan gubahan massa yang disesuaikan dengan kebutuhan dari program kurikulum untuk bangunan ini juga.

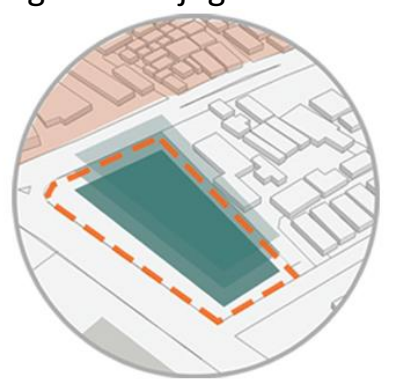

Setback GSB

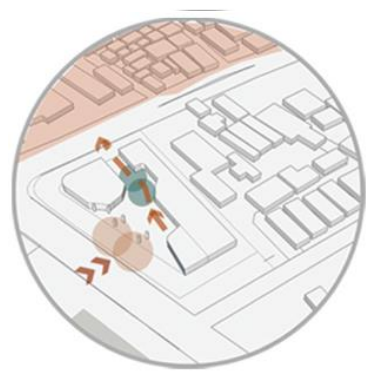

Bangunan dibagi 2 massa untuk aktivitas open space selain itu agar bangunan dapat menggunakan pengudaraan alami (tdk massive)

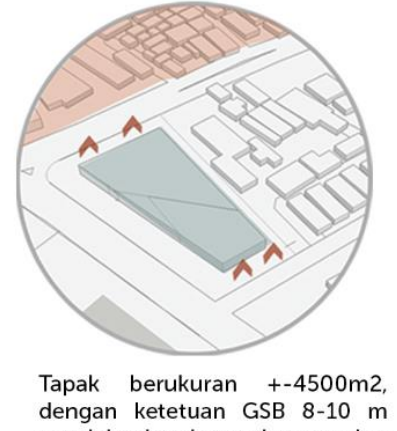
dengan ketetuan GSB $8-10 \mathrm{~m}$
untuk bagian depan dan samping

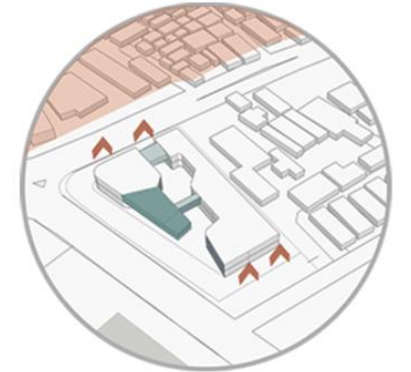

Luasan bangunan dimaksimalkan dengan program yang sudah ditentukan

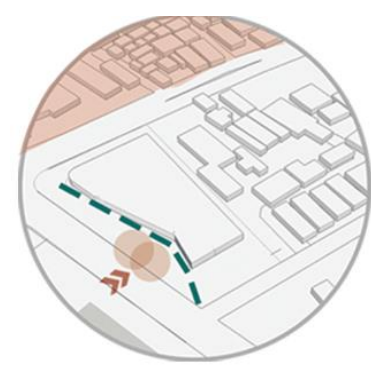

Bangunan merespon akses masuk kendaraan maupun pedestrian

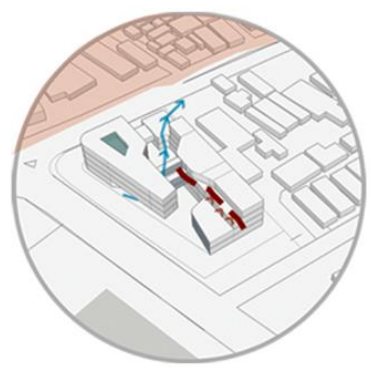

Bangunan dibuat lebih dinamis dengan adanya perbedaan ketinggian

Gambar 10. Proses Gubahan Massa

Sumber: Penulis, 2019

\section{DISKUSI DAN HASIL}

Fashion Bussiness \& Design Learning Space merupakan suatu fasilitas belajar untuk membantu milenial mengembangkan kemampuan berbisnis fashion maupun kemampuan mendesain suatu baju di bidang fashion industry yang sedang naik daun. Bangunan ini akan menjadi tempat untuk mengedukasi dan memberikan pengajaran vokasional kepada para business creator seputar fashion serta bangunan ini juga berfungsi sebagai tempat kumpul atau ruang komunitas para desainer dengan berbagi ruang dan cerita pengalaman di dunia fashion era millennial.

Learning Space ini dibagi menjadi dua bagian, yaitu kategori bisnis dan desain. Perbedaan kedua kategori tersebut terdapat di susunan kurikulumnya. Kategori pertama adalah fashion business dengan kurikulum yang berisi susunan kegiatan belajar teori seperti; fashion trend analysis, fashion, fashion phenomena, textile acknowledgement, marketing fashion, visual presentation, serta detail teknis di fashion runway, dll. 
Kategori kedua adalah fashion design dengan kurikulum yang berisi susunan kegiatan seperti desain dan produksi yang merupakan urutan pengenalan bahan kain, menggambar pola, menjahit pakaian, finishing atau post production, marketing penjualan, dll.

Fokus sasaran learning space ini akan lebih dikhususkan kepada milenial yang ingin membuka bisnis fashion dengan hasil originalitas ide dan desain yang diciptakan sendiri.

Terdapat tiga program utama dalam bangunan ini, yaitu learning, entertainment, dan commercial. Pertama, program learning ini dibagi lagi menjadi tiga bagian dengan program pembelajaran yang berberda. Fashion manufacturing adalah proses produksi pembuatan baju dari pemilihan bahan sampai ke tahap packaging. Fashion Marketing adalah proses pembelajaran terhadap memasarkan produk sendiri yang telah diproduksi. Program ini lebih membahas ke pemasaran produk dalam skala yang besar dan dapat bersaing di platform ecommerce. Fashion Business merupakan proses pembelajaran bagaimana menciptakan ide kreatif bisnis dan menentukan target konsumen serta karakter fashion yang ingin ditonjolkan. Fashion entertainment merupakan program bangunan yang direncanakan untuk mendorong para pelajar mengeluarkan ide dan mewadahi pelajar mencari inspirasi.

Commercial Area merupakan program bangunan yang direncanakan untuk menghasilkan penghasilan dari retail maupun fasilitas studio kerja bagi pelajar fashion student yang membutuhkan ruangan khusus. Kantin yang menunjang bagi para pelajar di sekitar sana. Berikut merupakan presentase besaran dari luasan program.

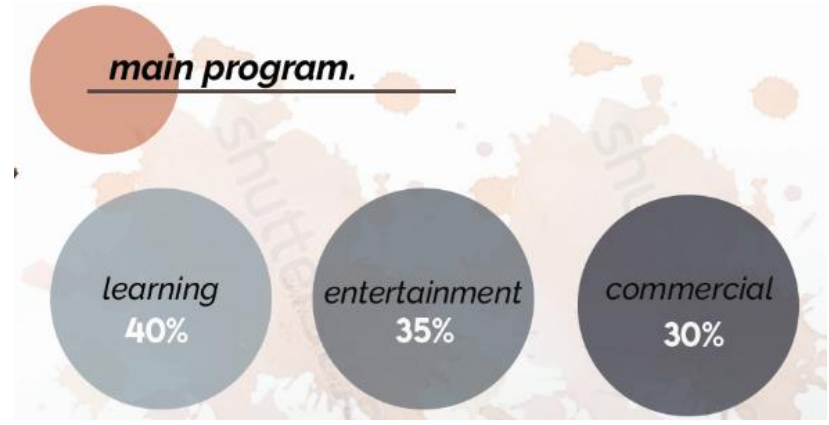

Gambar 11. Main Programs

Sumber: Penulis, 2019

Bangunan ini memiliki luas kurang lebih yaitu sekitar 7000m2 dengan ketinggian bangunan 4 lantai. Masing-masing lantai memiliki tinggii $4.5 \mathrm{~m}$ serta 6.5 di lantai dasar. Dengan fungsi dan program ruang yang mendukung konsep 'Collaborative Environment'. Konsep tersebut merupakan hasil analisa perilaku milenial terhadap cara kerja yang efektif dan efisien. Cara kerja milenial dengan berkolaborasi merupakan hal yang paling digemari oleh generasi milenial, sehingga dalam bangunan ini diterapkan banyak discussion area serta communal space yang menjadi wadah untuk memberikan kesempatan generasi milenial bekerja sama. Bangunan ini di desain agar fashion student dapat berkolaborasi satu dengan lainnya dan menciptakan suasana belajar yang nyaman.

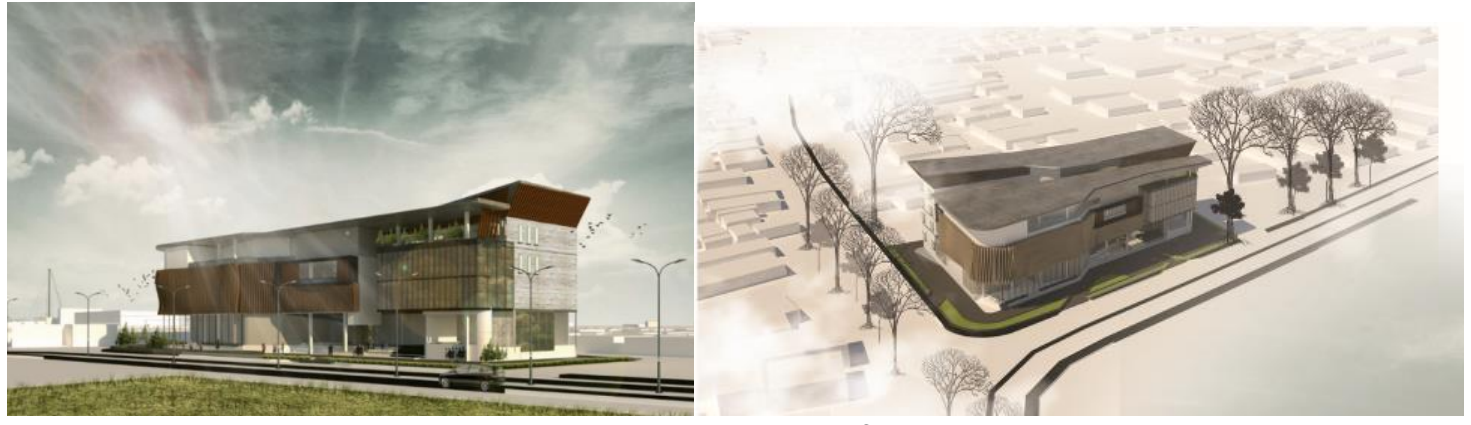

Gambar 12. Perspektif eksterior

Sumber: Penulis, 2019 
Selain ruangan yang membentuk 'efek kolaborasi' ini, ditunjang dengan kurikulum yang mengaharuskan student fashion business bekerja sama dengan student fashion design. Cara kerja ini dapat membentuk network dan komunitas baru antar milenial. Terdapat juga ruangan yang menunjang untuk bekerja dengan nyaman sebagai fashion student dengan fasilitas yang menunjang dan bersifat komersial. Ruangan ini dapat dijadikan tempat kerja, tempat menjahit, bersantai serta mencari ide. Ruangan ini dinamakan sebagai "collaborative play room".

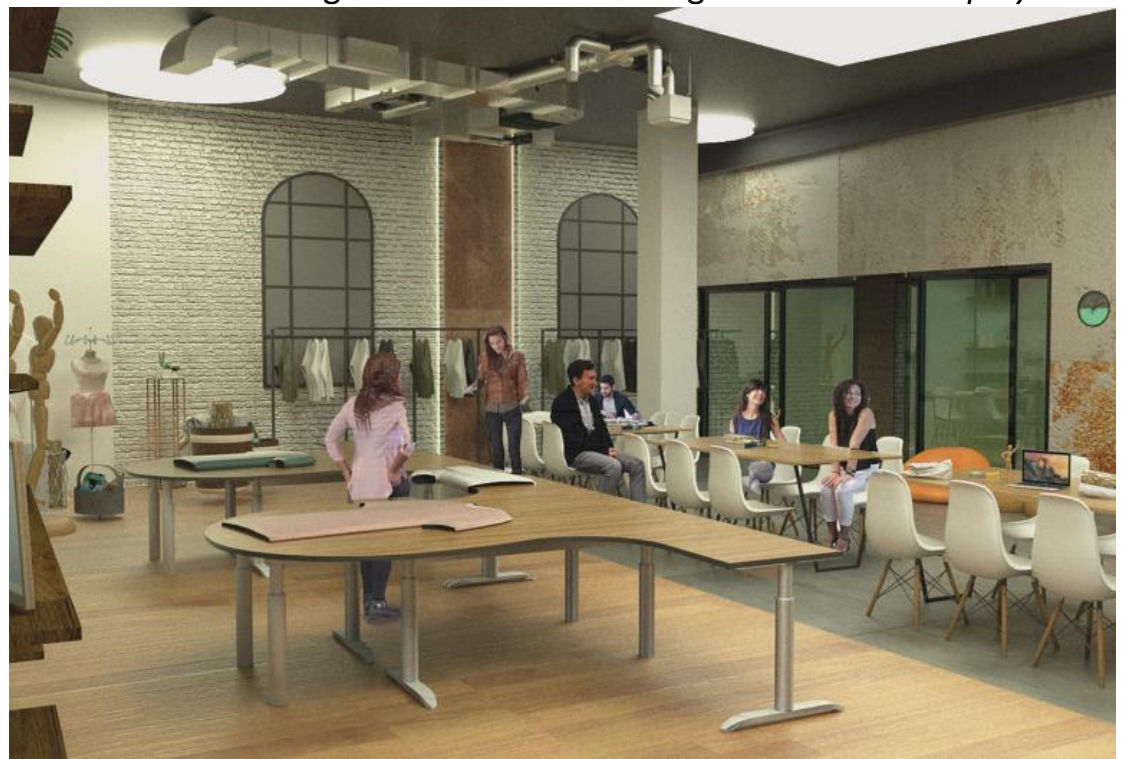

Gambar 13. Perspektif Interior

Sumber: Penulis, 2019

Sistem pengudaraan bangunan ini memakai pengudaraan alami dan pengudaraan buatan disebagian tempat agar menghemat dan memanfaatkan sumber daya yang ada. Berlaku juga terhadap sistem pencahayaan pada bangunan ini beberapa memanfaatkan cahaya alami dengan banyak bukaan agar sinar dapat masuk dengan leluasa. Berikut merupakan potongan penjelasan sistem pengudaraan dan pencahayaan.

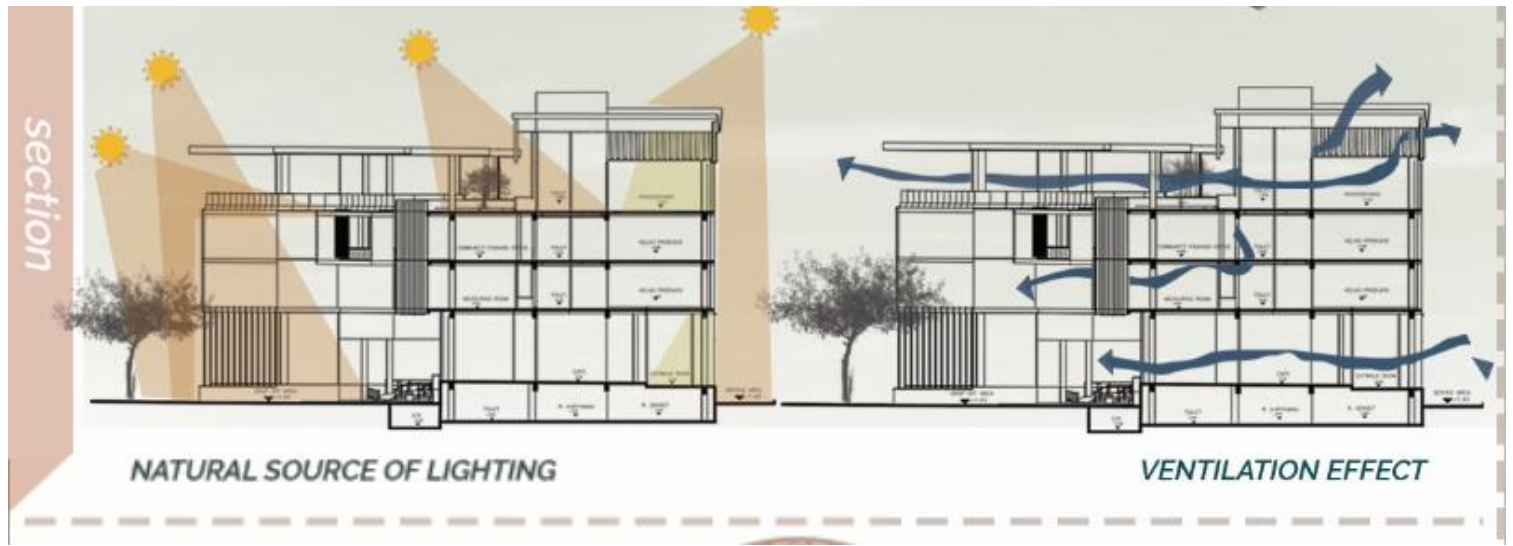

Gambar 14. Potongan Bangunan

Sumber: Penulis, 2019

Selain itu, tampak pada bangunan ini terdapat second skin dengan material kayu (150x20 $\mathrm{cm}$ ), dibuat dengan bentuk lebih dinamis agar mencirikan sebuah karakteristik kain yang lembut seakan sedang tertiup angin. Second skin ini di letakan pada fasad dinding di lantai dua dan tiga sehingga juga berfungsi sebagai privasi penutup kaca dari bagian gedung ini dan menjaga suhu udara dalam gedung bangunan ini agar tidak terpapar terlalu banyak sinar matahari dan membuat ruangan di dalamnya menjadi sejuk. 


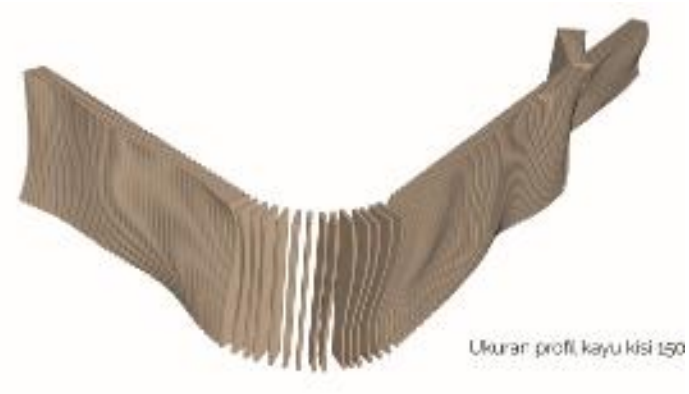

Gambar 15. Second Skin

Sumber: Penulis, 2019

\section{KESIMPULAN DAN SARAN \\ Kesimpulan}

Kesimpulan dari desain ini adalah menurut data statistik bahwa milenial mempunyai peluang yang besar dalam bisnis online fashion sehingga desain ini dibuat untuk milenial yang tertarik untuk mengambil kesempatan bisnis peluang tersebut dan mempelajarinya untuk membuka bisnis. Selain itu fasilitas belajar di sini mendukung dan mengikutii karaktertistik perilaku yang terdapat di generasi milenial dengan memperbanyak sarana diskusi, communal space serta ruang kerja yang menunjang milenial untuk berkolaborasi dan memecahkan masalah secara bersamaan.

\section{Saran}

Saran dari desain ini adalah perlu dipelajari lebih lanjut untuk detil kurikulum serta detil tektonik bangunan.

\section{REFERENSI}

Bennett, S., Maton, K., \& Kervin, L. (2008). The "digital natives" debate: A critical review of the evidence. British Journal of Educational Technology, 39(5), 775-786. https://doi.org/10.1111/j.1467-8535.2007.00793.x

Bekraf. (2016). Data Statistik dan Hasil Survei Khusus Ekonomi Kreatif. https://www.bekraf.go.id/pustaka/page/data-statistik-dan-hasil-survei-khusus-ekonomikreatif ( di akses 16 Febuari 2019)

Fisher, K. (2005). Linking Pedagogy and Space. Departement of Education and Training: Proposed Planning Principles (di akses 8 Febuari 2019)

Fourhooks (2015). The Generation Guide-Millennials, Gen X, Y, Z and Baby Boomers di http://fourhooks.com/marketing/the-generation-guide-millennials-gen-x-y-z-and-babyboomers-art5910718593/ (di akses 12 Febuari 2019)

Germanos, D. (2016). The PSD Method: Pedagogical Space Design. Aristotle University of Thessaloniki,Greece, 1-7.

Graham , R. (2017). This chart reveals a huge difference in how millennials and their parents spend money di https://www.businessinsider.sg/millennials-consumer-spending-twice-asmuch-at-restaurants-than-previous-generations-2017-7/ (di akses 15 Febuari 2019)

Highlight Media.( 2018). Potensi Jakarta Sebagai Barometer Trend Fashion Nasional dan Global di https://highlight.id/potensi-jakarta-indonesia-sebagai-barometer-trend-mode-nasionalglobal/ (di akses 17 Febuari 2019) 
Inggritha dan Vida. (2014). Tren Pembelian Online pada Generasi Milenial. Skripsi. Depok: Universitas Indonesia

Muhammad Sufyan. (2017). Pertumbuhan e-Commerce Indonesia Tertinggi di Dunia. https://www.liputan6.com/tekno/read/2957050/pertumbuhan-e-commerce-indonesiatertinggi-di-dunia (di akses 16 Febuari 2019)

Prasetya Mulya. (2018). Bisnis Kreatif Kini Didominasi dan Digemari Generasi Milenial, Mengapa?http://pmbs.ac.id/news/Bisnis_Kreatif_Kini_Didominasi_dan_Digemari_Generasi _Milenial,_Mengapaques (di akses 15 Febuari 2019)

Rappler. (2017). Infografis: Milenial Ogah Terlibat Sepenuhnya di Perusahaan? di https://www.rappler.com/indonesia/gaya-hidup/187169-infografis-millenial-ogah-terlibatperusahaan (di akses 15 Febuari 2019)

Septian, D. (2016). BPS: Jumlah e-Commerce di Indonesia Capai 26,2 Juta di https://www.liputan6.com/bisnis/read/2602680/bps-jumlah-e-commerce-di-indonesiacapai-262-juta (di akses 15 Febuari 2018)

Smith, T. and Nicholas, T. (2015). Understanding the Millennial Generation. Journal of Bussiness Diversity Vol 15(1), 39-44

Sweeny, R. T. (2006). Millennial Behaviours \& Demographics. University Librarian. 1-10

Whiteboards Journal. (2018). Melihat Kultur Kerja Baru Millenial di https://www.whiteboardjournal.com/ideas/human-interest/melihat-kultur-kerja-barumilennial/ (di akses 15 Febuari 2019) 
